\title{
Avaliação do nível de estresse em pacientes com lesão cervical não cariosa atendidos na Clínica de Odontologia da UFCG
}

\author{
Evaluation of the level of stress in patients with non-audious cervical injury at the UFCG Odontology Clinic
} Evaluación del nivel de estrés en pacientes con lesión cervical no cariosa atendidos en la Clínica de Odontología de UFCG Laerte Petrúcio Andrade CAVALCANTE ${ }^{1}$ José Henrique de Araújo $\mathbf{C R U Z}^{1}$

Camila Helena Machado da Costa FIGUEIREDO²

Luanna Abílio Diniz Melquíades de MEDEIROS ${ }^{2}$ Elizandra Silva da PENHA

Abrahão Alves de OLIVEIRA FILHO²

Gymenna Maria Tenório GUÊNES ${ }^{3}$

${ }^{1}$ Acadêmico(a), Curso de Graduação em Odontologia. Centro de Saúde e Tecnologia Rural, Universidade Federal de Campina Grande, UFCG $58708-110$ Patos-PB, Brasil ${ }^{2}$ Professor(a) Doutor(a), Curso de Graduação em Odontologia. Centro de Saúde e Tecnologia Rural, Universidade Federal de Campina Grande UFCG $58708-110$ Patos-PB, Brasil

\section{Resumo}

Introdução: As lesões cervicais não cariosas (LCNC) apresentam-se como uma perda irreversível dentária na região cervical sem o envolvimento bacteriano e possui etiologia multifatorial. Devido o estresse, a perda de tecido dental tem sido associada ao fator oclusal, comprovando a associação da lesão ao bruxismo, apertamento e contato prematuro. Objetivo: Avaliar o nível de estresse em pacientes LCNC atendidos na Clínica Escola de Odontologia da Universidade Federal de Campina Grande (UFCG). Metodologia: O estudo foi do tipo transversal, observacional, com abordagem indutiva e procedimento comparativo, descritivo, estratégia de coleta de dados através das fichas clínicas, exame clínico e um questionário Inventário de Sintomas de Estresse de Lipp (ISSL). Os dados foram registrados no banco de dados do programa de informática SPSS para Windows 7, versão 13.0 no período de Fevereiro a Setembro de 2018. A fase I corresponde à experiência de estresse nas ultimas 24 horas, a fase II na última semana e a fase III no último mês. A amostra foi por conveniência composta por 150 participantes. Resultados: $86(57,4 \%)$ eram do gênero feminino e $64(42,6 \%)$ do gênero masculino. Do gênero masculino, o maior número de participantes (33) apresentavam-se em fase de exaustão (Fase III), e de 86 pacientes do gênero feminino, o maior número (50) também se apresentavam em nível de exaustão. Quando questionados sobre o sistema estomatognático, a tensão muscular foi a mais relatada com 42,6\% (75 assertivas). Conclusão: Portanto, pacientes com LCNC apresentaram-se estressados e sujeitos a alterações bucais e sistêmicas.

Descritores: Análise do estresse dentário. Dentística Operatória; Odontologia.

\section{Abstract}

Introduction: Non-carious cervical lesions (LCNC) present as an irreversible loss of teeth in the cervical region without bacterial involvement and have a multifactorial etiology. Due to stress, the loss of dental tissue has been associated with the occlusal factor, proving the association of the lesion with bruxism, tightening and premature contact. Objective: To evaluate the level of stress in LCNC patients attended at the Clinical School of Dentistry of the Federal University of Campina Grande (UFCG). Methodology: The cross-sectional, observational study with an inductive approach and a comparative, descriptive procedure, data collection strategy through clinical charts, clinical examination and a Lipp Stress Symptom Inventory (ISSL) questionnaire. Data were recorded in the SPSS database for Windows 7, version 13.0 from February to September 2018. Phase I corresponds to the last 24 hours of stress experience, phase II in the last week, and phase III in the last month. The sample consisted of 150 participants. Results: $86(57.4 \%)$ were female and $64(42.6 \%)$ were male. Of the male gender, the largest number of participants (33) were in the phase of exhaustion (Phase III), and of the 86 female patients, the highest number (50) were also in the level of exhaustion. When asked about the stomatognathic system, muscle tension was the most reported with $42.6 \%$ (75 assertive). Conclusion: Therefore, patients with LCNC were stressed and subject to oral and systemic alterations.

Descriptors: Dental Stress Analysis; Dentistry, Operative; Dentistry.

\section{Resumen}

Introducción: Las lesiones cervicales no cariosas (LCNC) se presentan como una pérdida irreversible dental en la región cervical sin la implicación bacteriana y posee etiología multifactorial. Debido al estrés, la pérdida de tejido dental ha sido asociada al factor oclusal, comprobando la asociación de la lesión al bruxismo, aprieto y contacto prematuro. Objetivo: Evaluar el nivel de estrés en pacientes LCNC atendidos en la Clínica Escuela de Odontología de la Universidad Federal de Campina Grande (UFCG). El estudio fue de tipo transversal, observacional, con enfoque inductivo y procedimiento comparativo, descriptivo, estrategia de recolección de datos a través de las fichas clínicas, examen clínico y un cuestionario Inventario de Síntomas de Estrés de Lipp (ISSL). Los datos se registraron en la base de datos del programa informático SPSS para Windows 7, versión 13.0 en el período de febrero a septiembre de 2018. La fase I corresponde a la experiencia de estrés en las últimas 24 horas, la fase II en la última semana y la fase III en el último mes. La muestra fue por conveniencia compuesta por 150 participantes. Resultados: $86(57,4 \%)$ eran del género femenino y $64(42,6 \%)$ del género masculino. En el género masculino, el mayor número de participantes (33) se presentaban en fase de agotamiento (Fase III), y de 86 pacientes del género femenino, el mayor número (50) también se presentaban a nivel de agotamiento. Cuando se les preguntó sobre el sistema estomatognático, la tensión muscular fue la más reportada con el 42,6\% (75 asertivas). Conclusión: Por lo tanto, pacientes con LCNC se presentaron estresados y sujetos a alteraciones bucales y sistémicas.

Descriptores: Análisis del Estrés Dental; Operatoria Dental; Odontología.

\section{INTRODUÇÃO}

As lesões cervicais não cariosas apresentamse como uma perda irreversível da estrutura dentária na região cervical sem o envolvimento da ação de bactérias e possui etiologia complexa e multifatorial ${ }^{1}$. De acordo com a sua origem e as características clínicas das lesões cervicais não cariosas são classificadas em erosão, abrasão e abfração ${ }^{2,3}$.

Nesse aspecto, nos diversos segmentos da sociedade, em virtude das exigências sociais modernas, o estresse tem aumentado na vida das pessoas, podendo ser constatado em todos os âmbitos ${ }^{4}$. Ele é caracterizado como um conjunto de perturbações orgânicas e/ou psíquicas, provocadas por vários estímulos ou agentes agressores, forçando o organismo a reagir, de modo a manter a homeostase interna $^{5,6}$.

Em função do estresse, a perda de tecido dental na região cervical tem sido compreendida por 
diversos motivos, como o fator oclusal, que ocorre flexão na região cervical, comprovando a associação da lesão ao bruxismo, apertamento e contato prematuro $^{7}$, e o estado psicológico do paciente como a frustração e ansiedade, estando intimamente relacionado ao bruxismo ${ }^{8}$.

Por outro lado, a qualidade de vida é a noção eminentemente humana, relacionada ao grau de satisfação encontrado na vida familiar, amorosa, social, ambiental e valores existenciais. Para a Organização Mundial da Saúde, a qualidade de vida reflete a posição da pessoa na vida, no contexto da cultura onde vive seu sistema de valores, objetivos, expectativas, padrões e preocupações ${ }^{9}$, refletindo a compreensão dos indivíduos de que suas necessidades estão sendo satisfeitas ${ }^{10}$.

Logo, a prevalência das lesões cervicais não cariosas tem aumentado cada vez mais devido a diversos fatores, como hábitos dietéticos, tempo dos dentes em boca, tentativa maior de higiene dos dentes e hábitos para-funcionais ${ }^{11}$.

Diante das considerações expostas, gera-se a hipótese de que a prevalência das lesões cervicais não cariosas é elevada e está relacionada aos contatos oclusais para-funcionais e que, por sua vez, ao estresse, portanto, este estudo tem como objetivo avaliar o nível de estresse em pacientes com estas lesões cervicais não cariosas (LCNC) atendidos na Clínica Escola de Odontologia da Universidade Federal de Campina Grande (UFCG).

\section{MATERIAL E MÉTODO}

O estudo foi do tipo transversal, observacional, com abordagem indutiva e procedimento comparativo, descritivo, adotando como estratégia de coleta de dados ficha clínica, exame clínico na Disciplina de Propedêutica Estomatológica IV e um questionário conhecido como Inventário de Sintomas de Estresse de Lipp (ISSL). O universo do presente estudo foi composto por 200 pacientes no período de Fevereiro a Setembro de 2018. A amostra utilizada foi por conveniência, constituída por 150 pacientes que apresentavam LCNC em pelo menos um dente. Apenas participaram do estudo, os pacientes compreendidos na faixa etária maiores de 18 anos, de ambos os gêneros e que concordaram espontaneamente em submeter-se à pesquisa estando em atendimento na Clínica de Propedêutica Estomatológica IV após exame clínico e confirmação em ficha clínica. Foram excluídos pacientes portadores de necessidades especiais. O paciente recebeu o termo de consentimento livre e esclarecido (TCLE), estando de acordo a participar da pesquisa. O exame clínico foi realizado com o paciente, para analisar a presença de LCNC, sendo confirmada a presença da lesão o paciente estava apto a participar da pesquisa. O questionário de Lipp - Inventário de
Sintomas de Stress de Lipp - ISSL, foi elaborado por $\operatorname{Lipp}^{6}$ (2003) e tem por objetivo fornecer um nível de estresse dos participantes da pesquisa. Sua aplicação é rápida e leva aproximadamente 8 minutos e pode ser realizada individualmente. $\mathrm{O}$ questionário apresenta três quadros referentes às fases do estresse. $\mathrm{O}$ primeiro quadro, composto de 15 itens referem-se aos sintomas físicos e psicológicos experimentado nas últimas 24 horas. O segundo, composto de 15 itens, refere-se aos sintomas físicos e psicológicos, na última semana. $\mathrm{O}$ terceiro quadro, composto 23 itens relacionados aos sintomas físicos e psicológicos, no último mês. Alguns dos sintomas que aparecem no quadro 1 aparecem no 1uadro 3, mas com intensidade distinta. Sendo os sintomas muitas vezes repetidos, diferenciando-se somente em sua intensidade $\mathrm{e}$ severidade. Para avaliar o nível de estresse do paciente era analisada a quantidade de assertivas assinaladas pelos pacientes em cada fase. $\mathrm{O}$ paciente que relatasse o maior número de assertivas em uma das fases representaria sua condição de saúde relacionada ao estresse, como no quadro 1 considerado em fase de alerta, no quadro 2 na fase de resistência, e quadro 3 na fase de exaustão. Após coletados, os dados foram registrados na forma de banco de dados do programa de informática SPSS (Statistical Package for Social Sciences) para Windows 7, versão 13.0 e foram trabalhados pela forma descritiva. Os dados coletados durante o decorrer da pesquisa foram tabelados e submetidos à avaliação sob aprovação do comitê de ética CAAE: 05368818.5.0000.5181.

\section{RESULTADOS}

A amostra coletada consistiu de 150 pacientes participantes, sendo 86 do gênero feminino e 64 do gênero masculino, sem que houvesse distinção de idade, no período de Fevereiro a Setembro de 2018, após a aprovação do comitê de ética em pesquisa (Tabela 1).

\begin{tabular}{l|ll}
\multicolumn{2}{c}{ Tabela 1. Dados relativos ao gênero } \\
\hline Gênero & $\boldsymbol{N}^{\boldsymbol{o}}$ & Porcentagem (\%) \\
\hline Masculino & 64 & $42,6 \%$ \\
Feminino & 86 & $57,4 \%$ \\
Total & 150 & $100 \%$ \\
\hline
\end{tabular}

Os 150 participantes foram classificados em um dos três níveis de estresse segundo o inventário de sintomas de estresse de Lipp, a partir do maior número de assertivas respondidas em cada fase, segundo o gênero masculino (Tabela 2) e feminino (Tabela 3).

Tabela 2. Dados relativos à fase do estresse segundo o gênero masculino

\begin{tabular}{l|ll}
\hline Fase & $\boldsymbol{N}^{\boldsymbol{0}}$ & Porcentagem (\%) \\
\hline Fase I & 15 & $23,4 \%$ \\
Fase II & 16 & $25 \%$ \\
Fase III & 33 & $51,6 \%$ \\
Total & 64 & $100 \%$ \\
\hline
\end{tabular}

Quando os gêneros foram analisados separadamente, uma vez que a mulher tende a procurar os serviços de saúde com maior frequência 
em relação ao homem, foi constatado que dos 64 pacientes do gênero masculino atendidos na Clínica Escola de Odontologia da UFCG, o maior número (33 participantes) apresentava-se mais estressados, em fase três correspondente à exaustão, um estresse que perdura por um período de tempo de pelo menos um mês.

Tabela 3. Dados relativos à fase do estresse segundo o gênero feminino

\begin{tabular}{l|ll}
\hline Fase & $\boldsymbol{N}^{\mathbf{O}}$ & Porcentagem (\%) \\
\hline Fase 01 & 14 & $22,7 \%$ \\
Fase O2 & 22 & $19,3 \%$ \\
Fase 03 & 50 & $58 \%$ \\
Total & 86 & $100 \%$ \\
\hline
\end{tabular}

Já para o gênero feminino, foi constatado que das 86 pacientes atendidas, o maior número (50 participantes) apresentava-se mais estressados, também em fase três correspondente à exaustão, perdurando por um período de tempo de um mês.

Os pacientes foram questionados sobre aspectos direcionados ao sistema estomatognático (cabeça e pescoço) presente na Fase I do Inventário de Lipp, correspondente às últimas 24 horas, sem distinção de gênero e podendo responder mais de uma assertiva (Tabela 4).

Tabela 4. Dados relacionados à fase I, correspondentes às assertivas sobre o sistema estomatognático (cabeça e pescoço)

\begin{tabular}{l|ll}
\hline Fase I (cabeça e pescoço) & $\boldsymbol{N}^{\boldsymbol{O}}$ & Porcentagem \\
\hline Boca seca & 40 & $22,6 \%$ \\
Tensão muscular & 75 & $42,5 \%$ \\
Aperto na mandíbula & 42 & $23,7 \%$ \\
Respiração ofegante (bucal) & 20 & $11,2 \%$ \\
Total & 176 & $100 \%$ \\
\hline
\end{tabular}

Da amostra composta por 150 pacientes, 176 assertivas foram marcadas direcionadas ao sistema de cabeça e pescoço, relacionado à saúde bucal presente no questionário na fase I. A disfunção mais relatada pelos pacientes foi à tensão muscular, com média de $42,6 \%$ das desordens orais. Ficando evidente que o estresse tem influência na cavidade bucal e de cabeça e pescoço.

\section{DISCUSSÃO}

No estudo foi avaliado o nível de estresse dos 150 pacientes participantes da pesquisa, que apresentam LCNC em um ou mais elementos dentários, foi analisado o estresse por meio de um questionário específico. Foi observado que, do total dos participantes da pesquisa, 83 deles foram classificados na fase III, correspondendo a 55,3\% dos pacientes que apresentam LCNC encontram-se no mais alto nível de estresse, o nível de exaustão.

Para Petti ${ }^{12}$ o modo de vida do indivíduo e os envolvimentos dos seus problemas se relacionam com a sociedade, vinculando seu estado de saúde sistêmica e bucal ao seu cotidiano. Grande parte das pesquisas científicas abordam os efeitos negativos do estresse e as consequências nocivas que ele causa ao organismo e que por isso a prevenção e o combate ao estresse devem ser constantes na prática clínica por uma equipe de saúde ${ }^{13}$.

Assim como vários estudos comprovam ${ }^{14-16}$, o agente etiológico principal da LCNC não é a abrasão pela escovação, mas sim a sobrecarga oclusal nos dentes como resultado da má oclusão e/ou parafunção, associadas às altas concentrações de estresse tensional, que separam os prismas de esmalte e aceleram os processos cervicais não cariosos.

Corroborando com isso, o presente estudo mostrou que das assertivas envolvendo o sistema estomatognático, foi possível verificar a presença de tensão muscular elevada, correspondendo a 42,5\% das desordens nos pacientes com LCNC, uma vez que, o estresse estando presentes na vida social de cada indivíduo, as chances de ocorrerem são elevadas.

Para Silva ${ }^{17}$ o aumento de expectativa de vida da população e indivíduos com maior número de dentes na boca e estresse associado à vida moderna, faz com que haja aumento progressivo na prevalência de LCNC tornando-se uma preocupação para a Odontologia.

Sobre a abfração, ela tem como principal fator etiológico o grande esforço oclusal excêntrico com consequente flexão da estrutura dentária, fadiga dos cristais de hidroxiapatita e consequente surgimento da lesão. A principal causa da abfração pode ser atribuída a uma sobrecarga oclusal que na maioria das vezes causa uma flexão do dente no limite amelocementário ${ }^{18}$.

Além disso, níveis elevados de estresse, como observados nos resultados dos questionários aplicados em pacientes com LCNC (aperto de mandíbula $23,7 \%$ ) podem gerar flexão exagerada nos prismas de esmalte e consequentemente às lesões de abfração.

Um estudo realizado por Martins et al. ${ }^{19}$ teve por objetivo verificar a associação da classe econômica e do estresse com a ocorrência de disfunção temporomandibular (DTM). Este estudo apresentou uma amostra estatisticamente significativa de 354 indivíduos de ambos os sexos, pertencentes a diferentes classes econômicas da zona urbana do município de Piacatu, São Paulo, Brasil. Nele, tendo como base a metodologia empregada, pode-se concluir que não houve associação estatística significativa entre classe econômica e disfunção temporomandibular; entretanto observou-se associação direta entre estresse e DTM nos habitantes da zona urbana do município.

Comparando o estudo de Martins et al. ${ }^{19}$ a este, o estresse tem sido muito frequente em grandes centros urbanos, uma vez que a rotina exaustiva influencia diretamente em seu surgimento e consequentemente no aparecimento ou aumento de LCNC, propiciando o aparecimento de patologias orais, assim como a DTM, que de diversos fatores, pode-se originar do apertamento mandibular e tensão muscular, como relatada pelos pacientes deste estudo.

Além disso, foi percebida uma diferença entre os gêneros dos participantes da pesquisa, onde o 
número de participantes do sexo feminino foi maior em relação aos participantes do sexo masculino. As diferenças comportamentais poderiam explicar essa discrepância, sendo as mulheres mais propensas a terem cuidados com a sua saúde ${ }^{20}$.

O nível de estresse apresentado pelos pacientes do sexo masculino e do sexo femininos não apresenta discrepância, uma vez que os dois gêneros analisados foram classificados em sua maioria na fase III, que apresenta o maior nível de exaustão. Porém estudos feitos por Calais et al. ${ }^{21}$ para verificar o índice de estresse entre gêneros, as mulheres apresentaram maior nível de estresse quando comparado todos os grupos da pesquisa realizada.

Rugh e Harlan ${ }^{22}$ relataram que clinicamente era comum identificar sintomas de bruxismo em períodos de dificuldade da vida e conforme estes fatores estressantes se resolviam o bruxismo também desaparecia, evidenciando a presença do estresse como fator etiológico. Um estudo sugeriu a existência de uma relação entre o bruxismo e as LCNC, estimando que em sujeitos que apresentavam lesões cervicais em forma de cunha, a porcentagem com transtornos parafuncionais era de $97 \%$, logo, relacionados ao estresse ${ }^{23}$.

Visto isso, o estresse diário é capaz de promover grandes aumentos de tensão muscular e caso ele não seja tratado poderá desencadear, paralelamente às LCNC, o bruxismo. Além disso, percebe-se o apoio social reduzido em procurar alternativas para minimiza-lo, tornando-se necessário implementar estratégias de prevenção ao estresse entre todos.

Cruz et al. ${ }^{23}$ concluíram que faltam informações que comprovem a atuação do estresse como causador dos problemas bucais de forma direta e indireta, entretanto, evidencias apontam que problemas psicológicos como o estresse somatizados a outros fatores podem ocasionar desordens bucais.

Em virtude disso, faz-se necessárias medidas para recuperar a forma e função, fisiologia mastigatória, harmonia e estética entre os $\operatorname{arcos}^{24}$, em pacientes com LCNC e, sobretudo, medidas que intervenham na redução do estresse social.

\section{CONCLUSÃO}

Tendo como base a metodologia empregada, conclui-se que o estresse pode ter influência sobre o aparecimento de LCNC, uma vez que, grande parte dos participantes apresentavam-se em níveis elevados de estresse (Fase III correspondente a exaustão), outrossim, os pacientes possuíam condições bucais que propiciavam o aparecimento de desordens ao aparelho estomatognático, como a tensão muscular.

\section{REFERÊNCIAS}

1. Bartlett DW, Shah PA. Critical review of noncarious cervical (wear) lesions and the role of abfraction, erosion, and abrasion. J Dent Res.
2006;85(4):306-12.

2. Bonfim RA, Crozato E, Mazzilli LEN, Frias AC. Prevalence and risk factors of non-carious cervical lesions related to occupational exporuse to acid mists. Braz oral res. 2015;29(1):1-8.

3. Molena CCL, Rapoport A, Rezende CP, Queiroz CM, Denardin OVP. Relação entre lesões cervicais não cariosas e hábitos. Rev bras cir Cabeça Pescoço. 2008;37(4):206-111.

4. Ribeiro RP, Martins JT, Marziale MHP, Robazzi MLCC. O adoecer pelo trabalho na enfermagem: uma revisão integrativa. Rev esc enferm USP. 2012;46(2): 495-504.

5. Sardá JRJJ, Legal EJ, Jablonski Jr S.J. Estresse: conceitos, métodos, medidas e possibilidades de intervenção. São Paulo: Casa do Psicólogo; 2004.

6. Lipp MEN. Mecanismos neuropsicológicos do stress: teoria e aplicações clínicas. São Paulo: Casa do Psicólogo; 2003.

7. Rees JS, Jagger DC. Abfraction lesions: myth or reality? J Esthet Restor Dent. 2003;15(5):263-71.

8. Xhonga FA. Bruxism and its effect on the teeth. J Oral Rehabil. 1977;4(1):65-76.

9. Pedro A, Ribeiro J, Soler G, Bugdan A. Qualidade de vida em mulheres com incontinência urinaria. SMAD. 2011;7(2):63-70.

10. Rigoni ACC, Silva LF, Silva TP, Fernandes BP, Silva CL. Relações entre a educação física escolar, as práticas corporais e a qualidade de vida. Revista CPAQV. 2017;9(1).

11. Amaral SM, Abad EC, Maia KD, Weyne S, Oliveira MPRPB, Tunãs ITC. Lesões não cariosas: o desafio do diagnóstico multidisciplinar. Arq Int Otorrinolaringol. 2012;16(1):96-102.

12.Petti S. Lifestyle risk factors for oral cancer. Oral Oncol. 2009;45(4-5):340-50.

13.Souza MSVB. Revisitando o significado do estresse no contexto das organizações: uma breve revisão teórico-conceitual [monografia]. Brasília: Centro Universitário de Brasília; 2014.

14.Kliemann C. Lesões cervicais não cariosas por abrasão (escovação traumática). J Bras Clin Odontol Integr. 2002;6(33):204-9.

15.Pegoraro LF, Scolaro JM, Conti PC, Telles D, Pegoraro TA. Noncarious cervical lesions in adults. Prevalence and occlusal aspects. J Am Dent Assoc. 2005;136(12):1694-700.

16. Kliemann C. Avaliação da etiologia e prevalência de lesões cervicais não cariosas com o uso de microscopia clínica e questionários em superfícies vestibulares de pré-molares [tese]. São Paulo: Universidade Estadual Paulista; 2001.

17.Silva FML. Lesões cervicais não cariosas: Prevalência, severidade e correlação com fatores etiológicos [dissertação]. Uberlandia: Faculdade de Odontologia de Uberlândia - UFU; 2006.

18.Lee WC, Eakle WS. Possible role of tensile stress 
in the etiology of cervical erosive lesions of teeth. J Prosthet Dent. 1984;52(3):374-80.

19. Martins RF, Garcia AR, Garbin CAS, Sundefeld MLMM. Associação entre classe econômica e estresse na ocorrência da disfunção temporomandibular. Rev bras epidemiol. 2007;10(2):215-22.

20.Kelsall A, Decalmer S, McGuinness K, Woodcock A, Smith JA. Sex differences and predictors of objective cough frequency in chronic cough. Thorax. 2009;64(5):393-98.

21.Calais SL, Andrade LMBD, Lipp MEN. Diferenças de sexo e escolaridade na manifestação de stress em adultos jovens. Psicol Reflex crit. 2003;16(2):257-63.

22.Rugh JD, Harlan J. Nocturnal bruxism and temporomandibular disorders. Adv Neurol. 1988;49:329-41.

23. Cruz MCFN, Braga VAS, Garcia JGF, Lopes FF, Maia ECS, Valois EM. Condições bucais relacionadas com o estresse: uma revisão dos achados atuais. Rev Fac Odontol Porto Alegre. 2008;49(1):8-11.

\section{CONFLITO DE INTERESSES}

Os autores declaram não haver conflitos de interesse.

\section{AUTOR PARA CORRESPONDENCIA}

\section{José Henrique de Araújo Cruz}

henrique_araújo1992@ hotmail.com

Submetido em 28/03/2019

Aceito em 11/06/2019 